\title{
$\beta$-Hydroxybutyrate Activates the NF- KB Signaling Pathway to Promote the Expression of Pro-Inflammatory Factors in Calf Hepatocytes
}

\author{
Xiaoxia Shia,d Xinwei Lia,d Dangdang Li ${ }^{a}$ Yu Li ${ }^{a}$ Yuxiang Song ${ }^{a}$ Qinghua Deng ${ }^{a}$ \\ Jianguo Wang ${ }^{b}$ Yuhang Zhang ${ }^{c}$ Hongyan Ding ${ }^{a}$ Liheng Yin $^{\text {a }}$ Yuming Zhang ${ }^{a}$ \\ Zhe Wang $^{\text {a }}$ Xiaobing Li ${ }^{\mathrm{a}}$ Guowen Liu ${ }^{\mathrm{a}}$ \\ ${ }^{a}$ College of Veterinary Medicine, Jilin University, Changchun, ${ }^{b}$ College of Veterinary Medicine, \\ Northwest A\&F University, Yangling, 'College of Animal Science and Technology, Jilin Agricultural

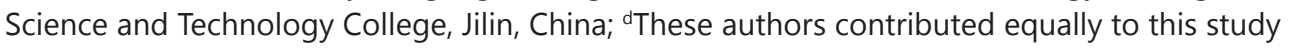

\section{Key Words}

Oxidative stress $\bullet N F-K B$ pathway $\bullet$ Inflammatory injury $\bullet$ Bovine hepatocytes

\begin{abstract}
Background/Aims: $\beta$-hydroxybutyrate (BHBA) is the major component of ketone bodies in ketosis. Dairy cows with ketosis often undergo oxidative stress. BHBA is related to the inflammation involved in other diseases of dairy cattle. However, whether BHBA can induce inflammatory injury in dairy cow hepatocytes and the potential mechanism of this induction are not clear. The NF- $\mathrm{kB}$ pathway plays a vital role in the inflammatory response. Methods: Therefore, this study evaluated the oxidative stress, pro-inflammatory factors and NF-KB pathway in cultured calf hepatocytes treated with different concentrations of BHBA, pyrrolidine dithiocarbamate (PDTC, an NF-KB pathway inhibitor) and N-acetylcysteine (NAC, antioxidant). Results: The results showed that BHBA could significantly increase the levels of oxidation indicators (MDA, NO and iNOS), whereas the levels of antioxidation indicators (GSH-Px, CAT and SOD) were markedly decreased in hepatocytes. The IKK $\beta$ activity and phospho-IKB $\alpha$ $(p-I \kappa B \alpha)$ contents were increased in BHBA-treated hepatocytes. This increase was accompanied by the increased expression level and transcription activity of p65. The expression levels of NF-KB-regulated inflammatory cytokines, namely TNF- $\alpha$, IL- 6 and IL- $1 \beta$, were markedly increased after BHBA treatment, while significantly decreased after NAC treatment. However, the $\mathrm{p}$-IKB $\alpha$ level and the expression and activity of p65 and its target genes were markedly decreased in the PDTC + BHBA group compared with the BHBA (1.8 mM) group. Moreover, immunocytofluorescence of $\mathrm{p} 65$ showed a similar trend. Conclusion: The present data indicate that higher concentrations of BHBA can induce cattle hepatocyte inflammatory injury through the NF-KB signaling pathway, which may be activated by oxidative stress.
\end{abstract}

Copyright (c) 2014 S. Karger AG, Basel 


\section{Introduction}

The liver is an important metabolic organ and regulates lipid metabolism in animals. Lipid metabolism disorders, such as fatty liver and ketosis, involve liver dysfunction and hepatocyte injury in the later stages of these diseases [1]. In general, dairy cows were subjected to a period of negative energy balance (NEB) during the transition period. Excessive NEB initiates fat mobilization and a subsequent increase in blood non-esterified fatty acid (NEFA) concentration $[2,3]$. Large amounts of NEFAs are transported into the liver and are involved in $\beta$-oxidation in the hepatocytes to generate more ATP to relieve the NEB. However, large amounts of NEFAs could not be completely oxidized and metabolized into ketones, such as $\beta$-hydroxybutyrate (BHBA), the major ketone body. Clinical studies have demonstrated that oxidative stress exists in dairy cows with ketosis $[4,5]$. BHBA is touted as an energy substrate that could be generated by the reduction of acetoacetate in the liver of all species and by the oxidation of butyrate exclusively in the ruminal epithelium. Moreover, BHBA is involved in ATP production, energy metabolism and thermogenesis [6]. Some studies have reported that BHBA could activate some signaling pathways as a signaling molecule and is involved in the regulation of food intake, thermogenesis, neuroprotection, and cell viability [6-9]. Even more remarkably, elevated concentrations of BHBA are related to endometritis and mastitis during the transition of dairy cows $[10,11]$. Further studies have demonstrated that inflammation could lead to hepatic injury in mice $[12,13]$. These studies suggest that BHBA may also be associated with the inflammatory injury of hepatocytes in dairy cattle. However, the underlying mechanisms in dairy cattle are not clear.

The nuclear factor NF- $\mathrm{KB}$ pathway plays a vital role in the inflammatory response and immunity [14]. The most classical NF- $\mathrm{\kappa B}$ binding form is a p65-p60 that remains associated with the I $\mathrm{kB}$ family of inhibitory proteins in the cytoplasm before activation [15]. The

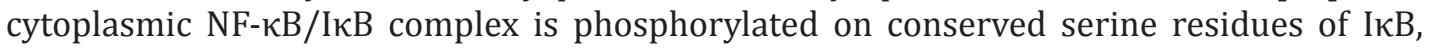
which leads to the dissociation of I $\kappa B$ from NF- $\kappa B$ and the subsequent translocation of p65 NF- $\kappa B$ to the nucleus. After tyrosine phosphorylation, p65 NF- $\kappa B$ binds to its cognate DNA-binding site in the promoter regions of specific genes, such as the pro-inflammatory factors tumor necrosis factor alpha (TNF- $\alpha$ ), interleukin 6 (IL-6) and interleukin 1 beta (IL1ß) [16]. A study reported that oxidative stress-induced hepatic injury could be regulated by the NF- $\kappa B$ signaling pathway in type I diabetic rats [17]. This result indicates that the $\mathrm{NF}-\kappa \mathrm{B}$ signaling pathway might mediate oxidative stress-induced hepatic injury. However, whether oxidative stress-induced hepatic injury is also regulated by the NF- $\kappa B$ pathway in dairy cattle is not clear. Moreover, oxidative stress is a common mechanism of liver injury [18] and activates the NF- $\kappa B$-mediated signaling pathway [19]. Dairy cows with severe NEB during early lactation increased oxidative stress $[20,21]$ and high blood concentrations of $\mathrm{BHBA}$. These results triggered our interest in exploring the relationships among the NF- $\kappa \mathrm{B}-$ mediated signaling pathway, oxidative stress and hepatocyte inflammatory injury in dairy cattle with NEB.

Therefore, the aim of this study was to investigate whether high levels of BHBA could activate the oxidative stress-mediated NF- $\mathrm{BB}$ signaling pathway to promote the synthesis of pro-inflammatory factors in cattle hepatocytes.

\section{Materials and Methods}

\section{Ethical approval of the study protocol}

All the experiments were performed in accordance with the Guiding Principles in the Use of Animals adopted by the Chinese Association for Laboratory Animal Sciences. All the animal procedures were approved by the Institutional Animal Care and Use Committee of Jilin University.

Isolation of cow primary hepatocytes

Calf (one-day-old, female, 45-50kg, health, fasting) primary hepatocytes were isolated and cultured as previously described [22]. Briefly, a scalpel was used to obtain the caudate lobe of the liver from a Holstein 
calf that was anesthetized with thiamylal sodium under sterile conditions. The liver was then quickly placed on a sterile bench, and bloodstains on the surface were removed with perfusion solution A (140 mM NaCl, $6.7 \mathrm{mM} \mathrm{KCl}, 10 \mathrm{mM}$ HEPES, $2.5 \mathrm{mM}$ glucose and $0.5 \mathrm{mM}$ EDTA, pH 7.4, 37 ${ }^{\circ} \mathrm{C}$ ), revealing the blood vessel on the cross section of the caudate process. A moderate blood vessel was intubated, and the liver was perfused with perfusion solution $\mathrm{A}\left(37^{\circ} \mathrm{C}\right)$ at a flow rate of $50 \mathrm{~mL} / \mathrm{min}$ for $15 \mathrm{~min}$. The liver was then perfused with solution B (140 mM NaCl, $6.7 \mathrm{mM} \mathrm{KCl,} 30 \mathrm{mM}$ HEPES, $2.5 \mathrm{mM}$ glucose and $5 \mathrm{mM} \mathrm{CaCl}, \mathrm{pH} 7.4,37^{\circ} \mathrm{C}$ ) at the same infusion rate for $3 \mathrm{~min}$. When the liquid became clear, the second step of the perfusion digestion, the addition of perfusate $\mathrm{C}\left(37^{\circ} \mathrm{C}, 20 \mathrm{~mL} / \mathrm{min}\right)$, was started. Before the final perfusion, all of the other coarse vessels were partially ligated so that the perfusate flowed slowly. Then, $100 \mathrm{~mL}$ of RPMI-1640 basic medium was added to the plate in which the digested liver was placed, and the blood vessels, fat and connective tissue were removed. Any parts of the liver caudate lobe that were incompletely digested were cut away, and the remainder of the liver parenchyma was cut into pieces and filtered sequentially through 100 mesh $(150 \mu \mathrm{m})$ and 200 mesh $(75 \mu \mathrm{m})$. The hepatocyte suspension was washed twice with basic medium before resuspension in adherent medium. The cell density was adjusted to $2 \times 10^{6}$ cells $/ \mathrm{mL}$ with adherent culture medium. The hepatocyte suspension was seeded into a six-well tissue culture plate ( $2 \mathrm{~mL} /$ well) and incubated at $37^{\circ} \mathrm{C}$ in $5 \% \mathrm{CO}_{2}$. After $4 \mathrm{~h}$, the culture medium was changed to growth medium (containing $10 \%$ fetal calf serum, benzylpenicillin and streptomycin). The medium was replaced with fresh medium every $24 \mathrm{~h}$.

\section{BHBA Preparation and Treatment}

The concentrations of BHBA used in this study were chosen according to the BHBA concentrations in cow serum [23]. Stock BHBA solution was prepared as follows: $1.206 \mathrm{~g}$ of BHBA powder was dissolved in $50 \mathrm{~mL}$ of distilled water, sterilized by filtration to obtain a concentration of $0.2 \mathrm{mM}$, and stored at $-20^{\circ} \mathrm{C}$. Before the treatment with BHBA, the cells were serum-starved overnight. The hepatocytes were subjected to the following treatments. For the time course experiments, the hepatocytes were treated with BHBA (1.8 $\mathrm{mM}$ ) for $0,1,3,6,9,12$ and $24 \mathrm{~h}$. For the dose response experiments, the hepatocytes were treated with BHBA, PDTC (pyrrolidine dithiocarbamate, an I $\mathrm{B} \alpha$ inhibitor) and N-acetylcysteine (NAC, one of the most used antioxidant drugs in liver diseases), respectively. PDTC can inhibit the activation of NF- $\kappa$ B specifically by suppressing the release of the inhibitory subunit I $\kappa B$ from the latent cytoplasmic form of NF- $\kappa B$. The hepatocytes were treated with 0, 0.6, 1.2, 1.8 and 2.4 mM BHBA, $10 \mu \mathrm{M}$ PDTC, $10 \mu \mathrm{M}$ PDTC + 1.8 mM BHBA $(\mathrm{PDTC}+\mathrm{BHBA})$ and $10 \mathrm{mM} \mathrm{NAC}+1.8 \mathrm{mM}$ BHBA $(\mathrm{NAC}+\mathrm{BHBA})$ for $24 \mathrm{~h}$. Each treatment was replicated nine times.

\section{MDA, NO, GSH-PX, SOD and CAT content determination}

The hepatocytes were harvested after incubation with different concentrations of BHBA for $24 \mathrm{~h}$ and washed twice in ice-cold phosphate-buffered saline (PBS). Then, the cells were lysed using P0013D (Beyotime, Jiangsu, China). The lysate was centrifuged at $12,000 \times g$ for $5 \mathrm{~min}$ at $4^{\circ} \mathrm{C}$. The supernatant was used to determine the content of malonaldehyde (MDA), nitric oxide (NO), glutathione peroxidase (GSH-Px), superoxide dismutase (SOD) and catalase (CAT) using the appropriate biochemical kits (Beyotime, Jiangsu, China) according to the manufacturer's instructions.

\section{IKK $\beta$ activity determination}

The hepatocytes were harvested after incubation with different concentrations of BHBA for $24 \mathrm{~h}$ and washed twice in ice-cold GENMED clean buffer (Reagent A, GenMed Scientifics Inc., USA) for 5 min at $300 \times g$ at $4^{\circ} \mathrm{C}$. Subsequently, the cells were treated with lysis buffer (Reagent B) and incubated for 30 minutes in an ice bath. The lysate was centrifuged for $5 \mathrm{~min}$ at $16,000 \times g$ at $4^{\circ} \mathrm{C}$, and the IKK $\beta$ activity in the supernatant was measured using a spectrophotometer and a biochemical kit (Reagent A, GenMed Scientifics Inc., USA) according to the manufacturer's instructions.

\section{RNA extraction and Real-time PCR}

Total hepatocyte RNA was extracted with TRIzol reagent (TaKaRa Biotechnology Co., Ltd., Tokyo, Japan) according to the supplier's protocol. The RNA concentration was determined using a K5500 MicroSpectrophotometer (Beijing Kaiao Technology Development Co., Ltd., Beijing, China) before reverse transcription polymerase chain reaction (RT-PCR). Approximately $5 \mu \mathrm{g}$ of total RNA was reverse-transcribed to cDNA in 20- $\mu$ L reactions using PrimeScript Reverse Transcriptase (TaKaRa Biotechnology Co., Ltd., Tokyo, 
Shi et al.: $\beta$-Hydroxybutyrate Activates the NF-KB Pathway to Induce Inflammatory Injury

Table 1. The primers sequences used for cDNA generation

\begin{tabular}{|c|c|c|c|}
\hline Gene & Sequence number & Primer sequences $\left(5^{\prime}-3^{\prime}\right)$ & Length (bp) \\
\hline NF-кB p65 & NM_001080242.2 & $\begin{array}{l}\text { For AGGACCAACCAGACCG } \\
\text { Rev TGTCACCAGGCGAGTTAT }\end{array}$ & 240 \\
\hline TNF $\alpha$ & NW_003104557.1 & $\begin{array}{l}\text { For CTGCCGGACTACCTGGACTAT } \\
\text { Rev CCTCACTTCCCTACATCCCTAA }\end{array}$ & 234 \\
\hline IL6 & NW_00310889.1 & $\begin{array}{l}\text { For AACGAGTGGGTAAAGAACGC } \\
\text { Rev CTGACCAGAGGAGGGAATGC }\end{array}$ & 144 \\
\hline IL1 $\beta$ & NW_003104294.1 & $\begin{array}{l}\text { For CTGAACCCATCAACGAAA } \\
\text { Rev ATGACCGACACCACCTGC }\end{array}$ & 190 \\
\hline GSH-Px & NM_001101113.2 & $\begin{array}{l}\text { For GCGGGAGCAGGACTTCTACGA } \\
\text { Rev CCCGATAGTGCTGGTCTGTGAA }\end{array}$ & 137 \\
\hline Mn SOD & NM_201527.2 & $\begin{array}{l}\text { For TTACATAAGGAGCAGGGACG } \\
\text { Rev CAGTGTAAGGCTGACGGTTT }\end{array}$ & 234 \\
\hline $\mathrm{Cu} / \mathrm{Zn} \mathrm{SOD}$ & BC 102432.1 & $\begin{array}{l}\text { For GAAGAGAGGCATGTTGGAGA } \\
\text { Rev CCAATTACACCACGAGCCAAA }\end{array}$ & 220 \\
\hline CAT & NM_001035386.1 & $\begin{array}{l}\text { For AGATACTCCAAGGCGAAGGTG } \\
\text { Rev AAAGCCACGAGGGTACCGAAC }\end{array}$ & 120 \\
\hline$\beta$-actin & BC 142413.1 & $\begin{array}{l}\text { For GCCCTGAGGCTCTCTTCCA } \\
\text { Rev GCGGATGTCGACGTCACA }\end{array}$ & 101 \\
\hline
\end{tabular}

Japan) according to the manufacturer's instructions. The primers were designed using Primer Express software (PE Applied Biosystems, Inc., Foster City, CA, USA; Table 1). The mRNA expression levels were estimated by real-time PCR analysis using FS Universal SYBR Green Real Master (Roche) on the 7500 RealTime PCR System (Applied Biosystems). The conditions were as follows: $95^{\circ} \mathrm{C}$ for 3 min, followed by 40 cycles of $95^{\circ} \mathrm{C}$ for $15 \mathrm{sec}$ and $60^{\circ} \mathrm{C}$ for $1 \mathrm{~min}$. All the reactions were run in triplicate. The relative expression levels were normalized to $\beta$-actin levels.

\section{Western Blotting}

The hepatocytes were harvested from the culture plates with PBS, and the total cellular proteins (TP) and nuclear proteins were extracted using a protein extraction kit and a nuclear protein extraction kit (Sangon Biotech Co., Ltd., Shanghai, China), respectively, according to the manufacturer's instructions. Sodium dodecyl sulfate-polyacrylamide gel electrophoresis (SDS-PAGE) separation was performed with 50 $\mu \mathrm{g}$ of protein per lane and with known molecular weight markers (Sangon Biotech Co., Ltd., Shanghai, China). The proteins were then electrophoretically transferred onto polyvinylidene fluoride (PVDF) membranes. Then, the membranes were incubated in blocking solution (5\% nonfat milk in Tris-HCl buffer solution [TBS]) for $6 \mathrm{~h}$ at $4^{\circ} \mathrm{C}$. The blocked membranes were hybridized overnight at $4^{\circ} \mathrm{C}$ with antibodies against NF- $\kappa B$ p65, phospho-IкB $\alpha(\mathrm{p}-\mathrm{I} \kappa \mathrm{B} \alpha), \mathrm{I} \kappa \mathrm{B} \alpha$, histone and $\beta$-actin. Next, the membranes were washed three times with TBS containing $0.1 \%$ Tween 20 for $5 \mathrm{~min}$ at room temperature with shaking, incubated with the appropriate peroxidase-conjugated secondary antibodies for $45 \mathrm{~min}$ at room temperature with shaking and then washed four times for $5 \mathrm{~min}$. An immunodetection analysis was performed using an enhanced chemiluminescence solution (ECL, Pierce Biotechnology Inc., Chicago, IL, USA). The relative expression

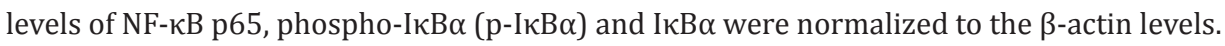

\section{Enzyme-linked immunosorbent assay (ELISA)}

After the hepatocytes were treated with BHBA, PDTC and NAC, respectively, as described above, the cell-free supernatants were subsequently centrifuged at $3000 \mathrm{rpm}$ for $20 \mathrm{~min}$ to extract the upper liquid for use in assays for the pro-inflammatory cytokines TNF- $\alpha$, IL- 6 and IL- $1 \beta$ with the bovine tumor necrosis factor alpha (TNF- $\alpha$ ) ELISA Kit, bovine interleukin-6 (IL-6) ELISA Kit and bovine interleukin-1 $\beta$ (IL-1 $\beta$ ) ELISA Kit (IBL, Germany), respectively, according to the manufacturer's instructions.

\section{Electrophoretic mobility shift assay (EMSA)}

Nuclear proteins were extracted using a nuclear protein extraction kit (Sangon Biotech Co., Ltd., Shanghai, China) according to the manufacturer's instructions. The special probe recognition sequence for NF- $\kappa$ B is $5^{\prime}$-AGTTGAGGGGACTTTCCCAGGC-3'. The probe was labeled with biotin by incubating at $37^{\circ} \mathrm{C}$ for $1 \mathrm{~h}$ and purified using centrifugal chromatography. The binding reaction was performed using the Lightshift EMSA Optimization and Control Kit (Pierce Biotechnology, Inc., Rockford, IL, USA) according to the manufacturer's instructions. An EMSA/gel-shift binding buffer containing $6 \mu \mathrm{g}$ of nuclear extract was incubated with the biotin-labeled probe for $20 \mathrm{~min}$ at room temperature. The nuclear protein complexes were separated by electrophoresis on non-denaturing 6\% polyacrylamide tris/borate/EDTA (TBE) gels and electrotransferred onto a nylon membrane. Then, the membranes were cross-linked using a UV cross-linker 
Fig. 1. Effects of BHBA treatment duration on I $\kappa \alpha$ phosphorylation in calf hepatocytes. Hepatocytes were treated with 1.8 mM BHBA for $0,1,3,6,9,12$ and 24 h. (A) Western blots of $\beta$-actin, I $\mathrm{KB} \alpha$ and $\mathrm{p}-\mathrm{I} \kappa \mathrm{B} \alpha$. (B) The phosphorylation ratio of I $\kappa \mathrm{B} \alpha$. The data are shown as the mean \pm SEM. *, statistical significance $(\mathrm{P}<0.05)$. **, statistical significance $(\mathrm{P}<0.01)$. The symbol * and ** indicate statistical differences with the control group $(0 \mathrm{~h})$.

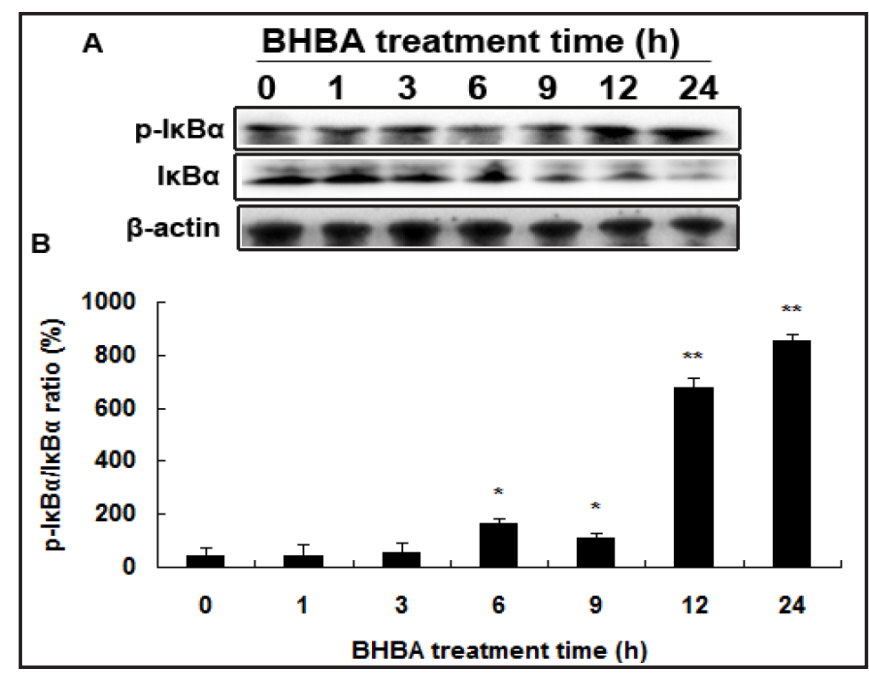

(Cany Precision Instruments Co., Ltd., Shanghai, China), and the biotin-labeled probe was detected using an enhanced chemiluminescence solution (ECL; Pierce Biotechnology Inc., Chicago, IL, USA).

\section{Immunocytofluorescence}

Calf hepatocytes were grown on glass coverslips to $90 \%$ confluency and subjected to BHBA or PDTC treatment as described above. Upon completion of the treatment, the coverslips were washed with PBS, fixed with $4 \%$ paraformaldehyde for $20 \mathrm{~min}$ at room temperature, subjected to antigen retrieval with EDTA $\bullet 2 \mathrm{Na}\left(95^{\circ} \mathrm{C}, 5 \mathrm{~min}\right)$ and permeabilized with $0.1 \%$ Triton X-100 (Sigma-Aldrich, St. Louis, MO). After further washing, the hepatocytes were exposed to the primary antibody NF- $\kappa \mathrm{B}$ p 65 at $4{ }^{\circ} \mathrm{C}$ overnight and then incubated with goat anti-rabbit IgG conjugated with cy3 (Beyotime, China) at room temperature for $30 \mathrm{~min}$ and counterstained with Hoechst 33258 (Beyotime, China). The coverslips were observed and photographed using laser-scanning confocal microscopy (Fluoview FV1200, Olympus, Japan).

\section{Chemical reagents and antibodies}

Collagenase IV, heparin sodium, fetal bovine serum and RPMI-1640 medium were purchased from Gibco (Grand Island, NY, USA). HEPES, insulin, $\beta$-hydroxybutyrate powder, NAC and the NF- $\kappa$ B inhibitor PDTC were provided by Sigma-Aldrich (St. Louis, MO, USA). Vitamin C, dexamethasone acetate, penicillin, streptomycin and other chemicals were purchased from Baoman Biotechnology (Shanghai, China). The $\beta$-actin antibody was purchased from Santa Cruz Biotechnology (Santa Cruz, CA, USA). The p-IкB $\alpha$ and I $\kappa \mathrm{B} \alpha$ antibodies were provided by Cell Signaling Technology (Danvers, MA, USA). The NF- $\kappa$ B p65 antibody was supplied by Abcam (Cambridge, MA, USA). Six-well plates and filters were purchased from Corning Incorporated (Corning, NY, USA).

\section{Statistical analysis}

The results are presented as the mean \pm SEM and were analyzed using SPSS (Statistical Package for the Social Sciences) 13.0 software (SPSS Incorporated, Chicago, IL, USA). Nine replicate samples were used for each condition. The differences among the groups were compared using independent sample Student's $t$-tests. A $p$ value lower than 0.05 was considered statistically significant (labeled with one star), and a $p$ value lower than 0.01 was considered highly significant (labeled with two stars).

\section{Results}

Effects of the duration of BHBA treatment on $I \kappa B \alpha$ phosphorylation in bovine hepatocytes (time course experiment)

To confirm the optimum time of the BHBA treatment in this study, the protein expression level of I $\mathrm{B} \alpha$ was detected by western blotting. The results showed that the phosphorylation level of $\mathrm{I} \kappa \mathrm{B} \alpha(\mathrm{p}-\mathrm{I} \kappa \mathrm{B} \alpha / \mathrm{I} \kappa \mathrm{B} \alpha)$ was higher at 6, 9, 12 and $24 \mathrm{~h}$ in the BHBA-treated groups, with the highest level at $24 \mathrm{~h}$ compared with the control group (Fig. $1 \mathrm{~A}, \mathrm{~B}$ ). 
Table 2. The content of oxidation markers and the activity of antioxidation markers. Oxidation and antioxidation markers in calf hepatocytes. Hepatocytes were treated with 0, 0.6, 1.2, 1.8 and 2.4 mM BHBA. The intracellular levels of the oxidation markers MDA and NO and the antioxidation markers GSH-Px, SOD and CAT were measured using commercial kits. The data are shown as the mean \pm SEM. a, b and c, the same letter indicates no significant difference $(\mathrm{P}>0.05)$, different letters mean a significant difference $(\mathrm{P}<0.05 / \mathrm{P}<0.01)$

\begin{tabular}{cccccc}
$\begin{array}{c}\text { markers } \\
\text { BHBA concentration }\end{array}$ & MDA (nmol/mg) & $\begin{array}{c}\text { NO } \\
(\mu \mathrm{mol} / \mathrm{L})\end{array}$ & GSH-Px $(\mathrm{mU} / \mathrm{mg})$ & $\begin{array}{c}\text { SOD } \\
(\mathrm{U} / \mathrm{mg})\end{array}$ & $\begin{array}{c}\text { CAT } \\
(\mathrm{U} / \mathrm{mg})\end{array}$ \\
\hline $0 \mathrm{mM}$ & $4.1119 \pm 0.525^{\mathrm{a}}$ & $72.41 \pm 3.4881^{\mathrm{a}}$ & $1800 \pm 13.113^{\mathrm{a}}$ & $18.67 \pm 0.5038^{\mathrm{a}}$ & $14.53 \pm 0.1503^{\mathrm{a}}$ \\
$0.6 \mathrm{mM}$ & $5.0413 \pm 0.608^{\mathrm{a}}$ & $77.52 \pm 3.1272^{\mathrm{a}}$ & $1780 \pm 12.176^{\mathrm{a}}$ & $17.89 \pm 0.5769^{\mathrm{a}}$ & $14.38 \pm 0.1576^{\mathrm{a}}$ \\
$1.2 \mathrm{mM}$ & $6.901 \pm 0.6899^{\mathrm{b}}$ & $88.56 \pm 2.265^{\mathrm{b}}$ & $1626 \pm 11.293^{\mathrm{b}}$ & $15.27 \pm 0.4093^{\mathrm{b}}$ & $13.84 \pm 0.1409^{\mathrm{b}}$ \\
$1.8 \mathrm{mM}$ & $8.532 \pm 0.4876^{\mathrm{c}}$ & $93.67 \pm 6.573^{\mathrm{b}}$ & $1587 \pm 19.203^{\mathrm{b}}$ & $14.78 \pm 0.4208^{\mathrm{b}}$ & $13.72 \pm 0.1420^{\mathrm{b}}$ \\
$2.4 \mathrm{mM}$ & $9.157 \pm 0.4291^{\mathrm{c}}$ & $89.29 \pm 6.328^{\mathrm{b}}$ & $1526 \pm 12.192^{\mathrm{c}}$ & $14.02 \pm 0.4073^{\mathrm{b}}$ & $13.53 \pm 0.1407^{\mathrm{c}}$
\end{tabular}
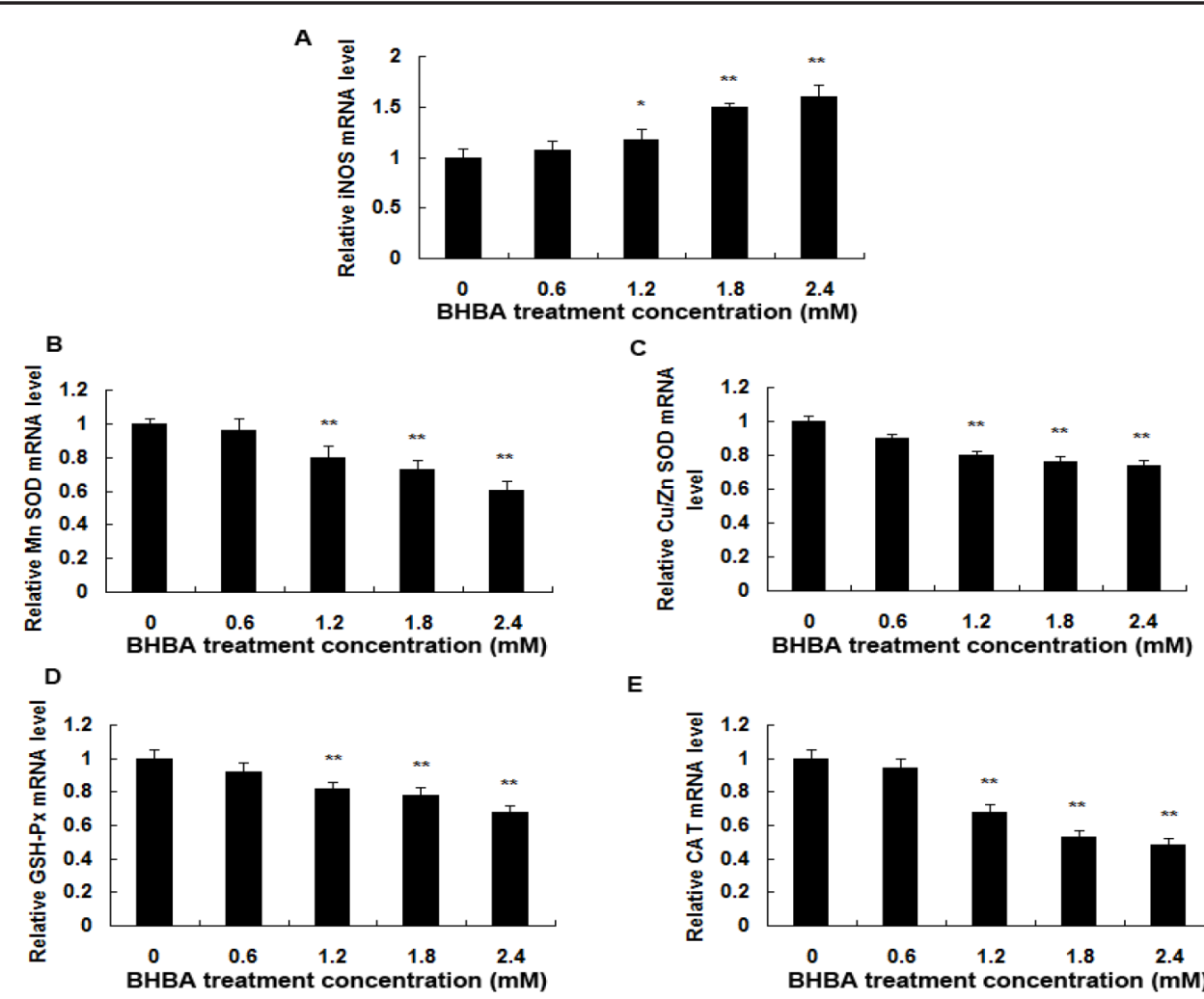

E

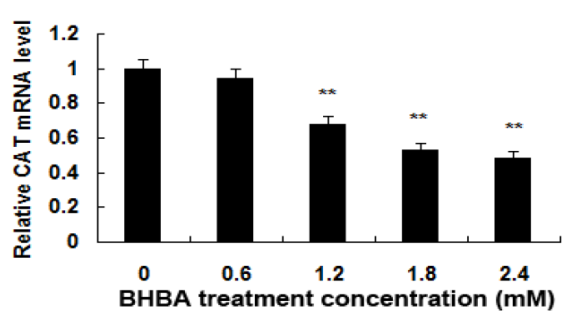

Fig. 2. Effects of different concentrations of BHBA on the oxidation markers MDA and NO and iNOS and the antioxidation markers SOD, CAT and GSH-Px in calf hepatocytes. Hepatocytes were treated with $0,0.6,1.2$, 1.8 and $2.4 \mathrm{mM}$ BHBA. (A) The mRNA level of iNOS. (B) The mRNA level of Mn SOD. (C) The mRNA level of $\mathrm{Cu} / Z n$ SOD. (D) The mRNA level of GSH-Px. (E) The mRNA level of CAT. The data are shown as the mean \pm SEM. *, statistical significance $(\mathrm{P}<0.05) .{ }^{* *}$, statistical significance $(\mathrm{P}<0.01)$. The symbol ${ }^{*}$ and ${ }^{* *}$ indicate statistical differences with the control group (no BHBA).

Effects of different concentrations of BHBA on the oxidation markers MDA, NO and iNOS and the antioxidation markers SOD, CAT and GSH-Px (dose response experiment)

The quantities of MDA and NO showed a significant upward trend in all the BHBAtreated groups compared with the control, and the iNOS mRNA expression showed a similar result (Table 2 and Fig. 2 A). Moreover, the mRNA expression and activity of SOD (Mn SOD and $\mathrm{Cu} / \mathrm{Zn} \mathrm{SOD}$ ), CAT and GSH-Px showed a significant downward trend in all the BHBAtreated groups (Table 2 and Fig. 2 B, C, D, E). 


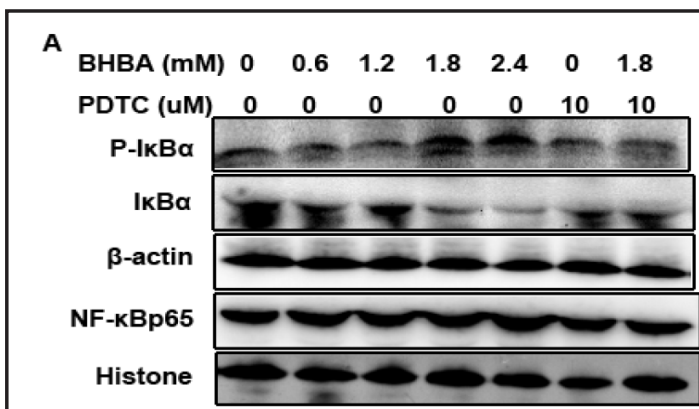

B

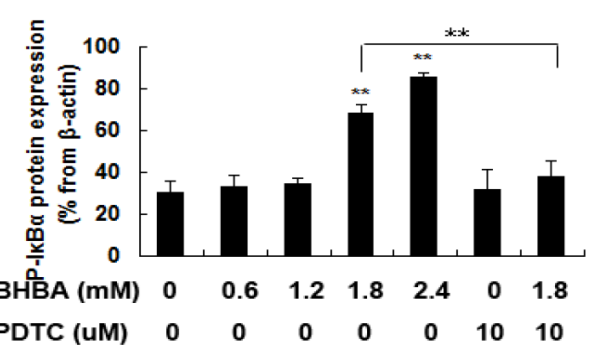

D

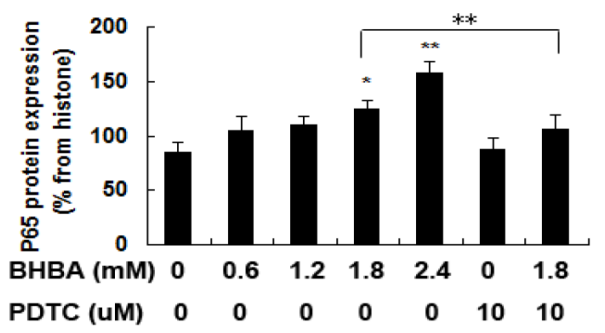

$\mathbf{F}$

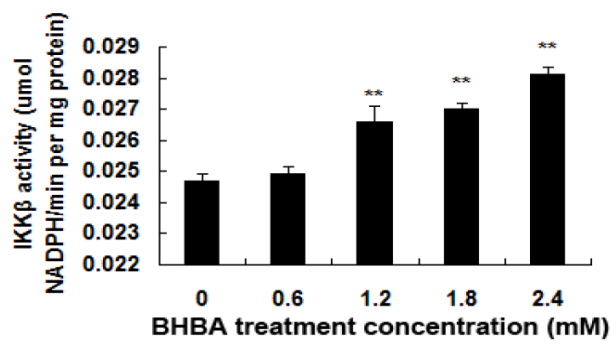

C

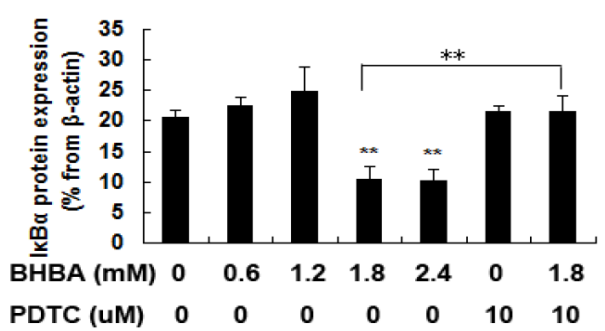

E

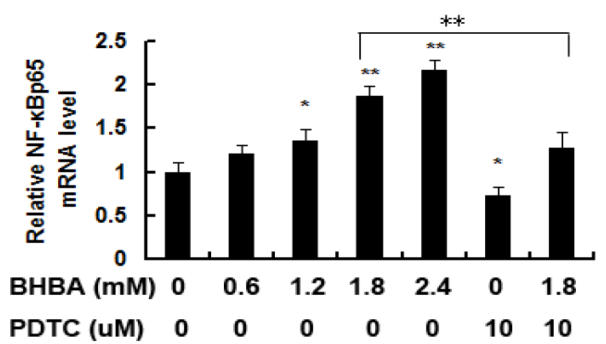

Fig. 3. BHBA activates the NF- $\kappa B$ signaling pathway in calf hepatocytes. Hepatocytes were treated with 0 , 0.6, 1.2, 1.8 and 2.4 mM BHBA, $10 \mu \mathrm{M}$ PDTC and $10 \mu \mathrm{M}$ PDTC + $1.8 \mathrm{mM}$ BHBA (PDTC + BHBA). (A) Western

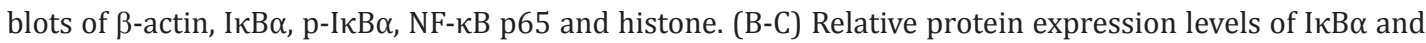
$\mathrm{p}$-I $\kappa \mathrm{B} \alpha$ normalized to $\beta$-actin. (D) Relative protein expression levels of p65 normalized to histone. (E) The mRNA levels of p65. (F) The activity of IKK $\beta$ in response to different concentrations of BHBA. The data are shown as the mean \pm SEM. *, statistical significance $(\mathrm{P}<0.05) .{ }^{* *}$, statistical significance $(\mathrm{P}<0.01)$. The symbol $^{*}$ and ** indicate statistical differences with the control group (no BHBA and no PDTC), and the two groups which marked with horiziontal line are statistical differences.

\section{BHBA activates the NF- $\kappa B$ pathway in bovine hepatocytes}

The NF- $\kappa B$ pathway is important for the inflammatory response and immunity. To determine the effect of BHBA on the NF- $\kappa B$ pathway, the activities of IKK $\beta$, I $\kappa B \alpha$ protein and p65 were measured after the BHBA and PDTC treatments using the activity assay kit, western blotting, real-time PCR, EMSA and immunocytofluorescence. The results showed that the activity of IKK $\beta$ increased in a BHBA-dependent manner and peaked in the $2.4 \mathrm{mM}$ BHBA treatment group (Fig. 3 F). Similarly, the phosphorylation levels of I $\kappa B \alpha$ also increased in a BHBA-dependent manner and were significantly higher in the $1.8 \mathrm{mM}$ and $2.4 \mathrm{mM}$ BHBAtreated groups than in the control group but were significantly lower in the PDTC + BHBA group than in the $1.8 \mathrm{mM}$ BHBA-treated group (Fig. $3 \mathrm{~A}, \mathrm{~B}, \mathrm{C}$ ). Additionally, the mRNA and nucleoprotein levels, as well as the transcription activity of p65, gradually increased after the BHBA treatment, with the highest levels in the $2.4 \mathrm{mM}$ BHBA-treated group, but they significantly decreased in the PDTC + BHBA group compared with the $1.8 \mathrm{mM}$ BHBA-treated 


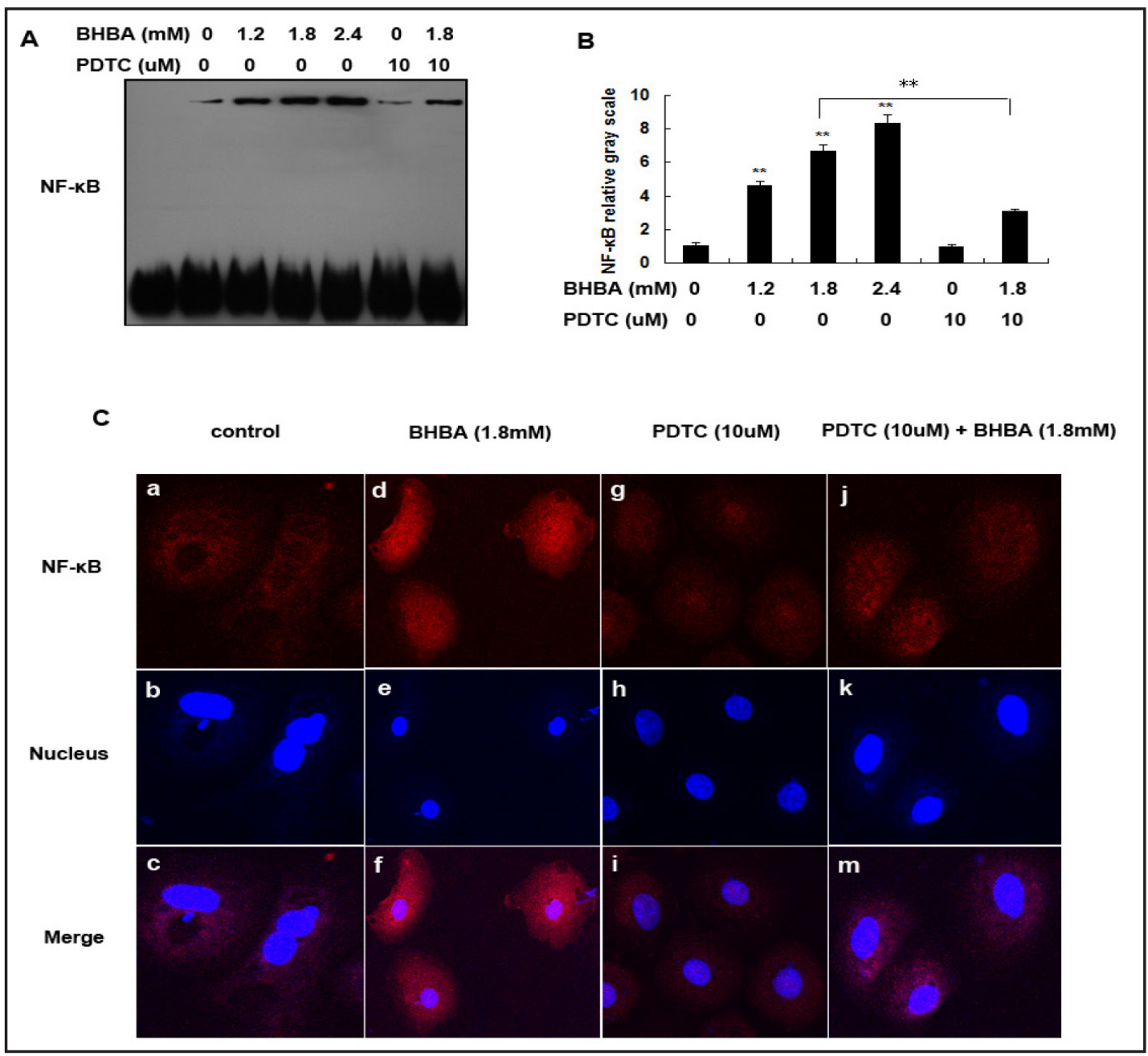

Fig. 4. Transcriptional activity and immunofluorescence staining of NF- $\kappa B$ p65 in calf hepatocytes. Hepatocytes were treated with $0,1.2,1.8$ and $2.4 \mathrm{mM}$ BHBA, $10 \mu \mathrm{M}$ PDTC and $10 \mu \mathrm{M}$ PDTC $+1.8 \mathrm{mM}$ BHBA (PDTC + BHBA). (A) EMSA result of NF- $\kappa$ B. (B) Relative gray scale of NF- $\kappa$ B. (C) Immunofluorescence staining of NF- $\kappa$ B p65 (a, d, g and j) in calf hepatocytes. Images (c, f, i and m) were merged with Hoechst 33258 staining images $(b, e, h$ and $k)$. The data are shown as the mean \pm SEM. *, statistical significance $(\mathrm{P}<0.05)$. ${ }^{* *}$, statistical significance $(\mathrm{P}<0.01)$. The symbol ${ }^{*}$ and ${ }^{* *}$ indicate statistical differences with the control group (no BHBA and no PDTC), and the two groups which marked with horiziontal line are statistical differences.

group (Fig. 3 A, D, E; Fig. 4 A, B). To further confirm that p65 translocates to the nucleus in bovine hepatocytes after BHBA treatment, immunocytofluorescence was performed. Figure $4 \mathrm{C}$ showed a similar trend as the EMSA results. Overall, these results indicate that a certain concentration of BHBA can activate the NF- $\kappa$ B pathway in a dose-dependent manner in cattle hepatocytes.

Effects of BHBA on the pro-inflammatory factors TNF- $\alpha, I L-6$ and $I L-1 \beta$ in bovine hepatocytes

The results demonstrated that the mRNA expression of TNF- $\alpha$, IL- 6 and IL- $1 \beta$ showed an increasing trend after the BHBA treatment and were significantly higher in the $1.8 \mathrm{mM}$ and $2.4 \mathrm{mM}$ BHBA-treated groups than in the control group but showed a decreasing trend in the PDTC + BHBA group compared with the 1.8 mM BHBA-treated group (Fig. 5 A, C, E). The quantities of TNF- $\alpha$, IL- 6 and IL- $1 \beta$ showed a similar result, which further supports the results of the real-time PCR (Fig. 5 B, D, F). These results suggest that BHBA can significantly 


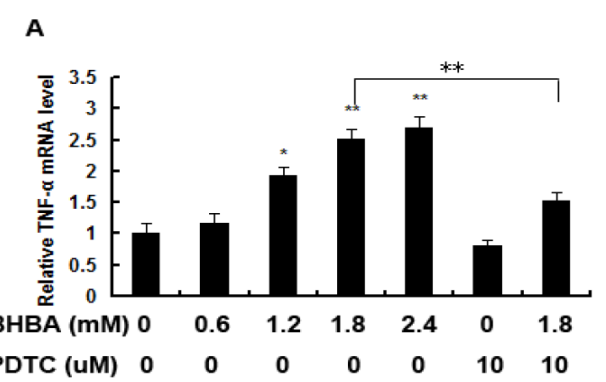

C

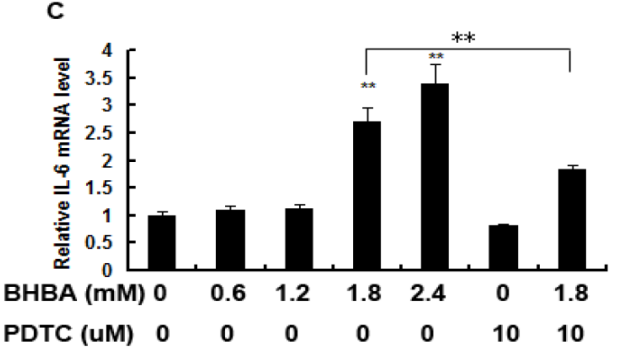

E

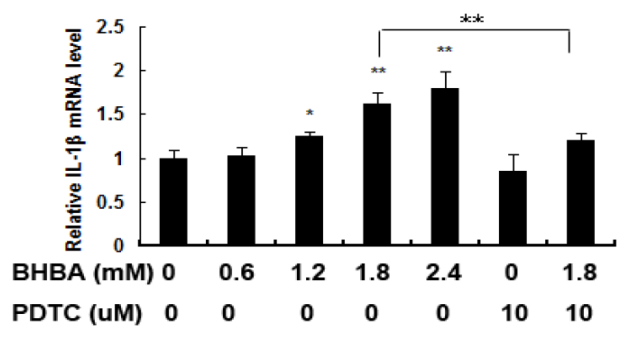

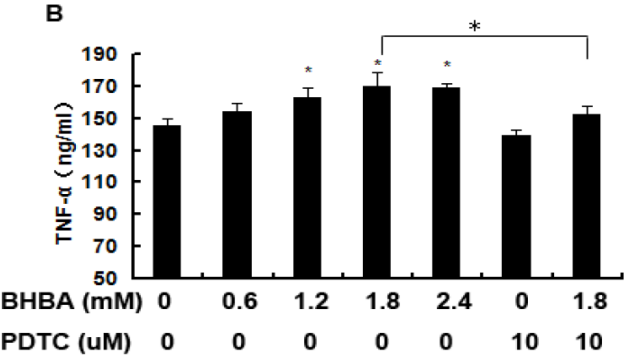

D

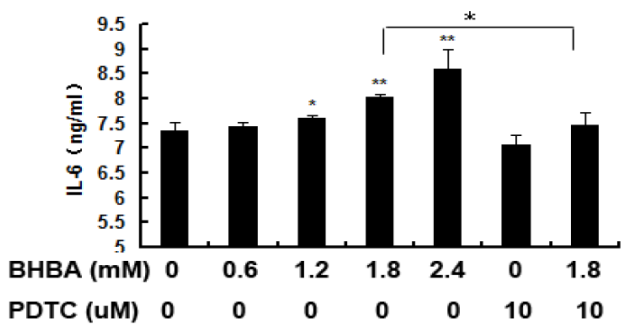

$\mathbf{F}$

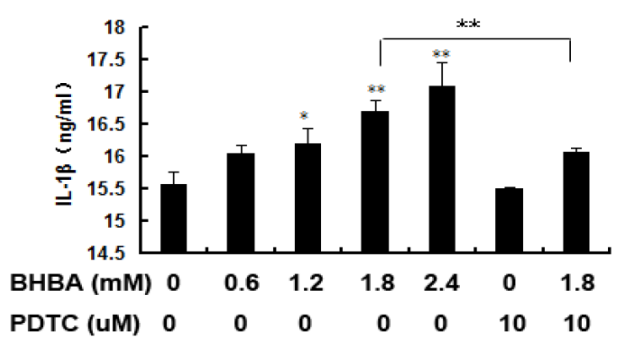

Fig. 5. BHBA-activated NF- $\kappa B$ signaling pathway activates the expression of pro-inflammatory factors in calf hepatocytes. Hepatocytes were treated as described in Figure 3. (A) The mRNA level of TNF- $\alpha$. (B) ELISA of TNF- $\alpha$. (C) The mRNA level of IL-6. (D) ELISA of IL-6. (E) The mRNA level of IL-1 $\beta$. (F) ELISA of IL-1 $\beta$. The data are shown as the mean \pm SEM. ${ }^{*}$, statistical significance $(\mathrm{P}<0.05) .{ }^{* *}$, statistical significance $(\mathrm{P}<0.01)$. The symbol * and ** indicate statistical differences with the control group (no BHBA and no PDTC), and the two groups which marked with horiziontal line are statistical differences.

upregulate the mRNA expression of pro-inflammatory factors and increase the release of proinflammatory factors in bovine hepatocytes. Taken together, these results demonstrate that BHBA can promote the expression of pro-inflammatory factors by activating the oxidative stress-medicated NF- $\kappa B$ pathway in cattle hepatocytes.

Effects of NAC on the pro-inflammatory factors TNF- $\alpha$, IL-6 and IL-1 $\beta$ in bovine hepatocytes

In order to identify that pro-inflammatory responses are induced by oxidative stress, the quantities of TNF- $\alpha$, IL- 6 and IL- $1 \beta$ were measured by ELISA after the BHBA and NAC treatments. The results demonstrated that the quantities of TNF- $\alpha$, IL- 6 and IL-1 $\beta$ significantly decreased in the NAC + BHBA group compared with the $1.8 \mathrm{mM}$ BHBA-treated group (Fig. $6 \mathrm{~A}, \mathrm{~B}, \mathrm{C}$ ).

\section{Discussion}

High concentrations of BHBA can induce post-partum diseases, poorer reproduction and lower milk production in transition dairy cattle [2]. In the present study, we have shown 


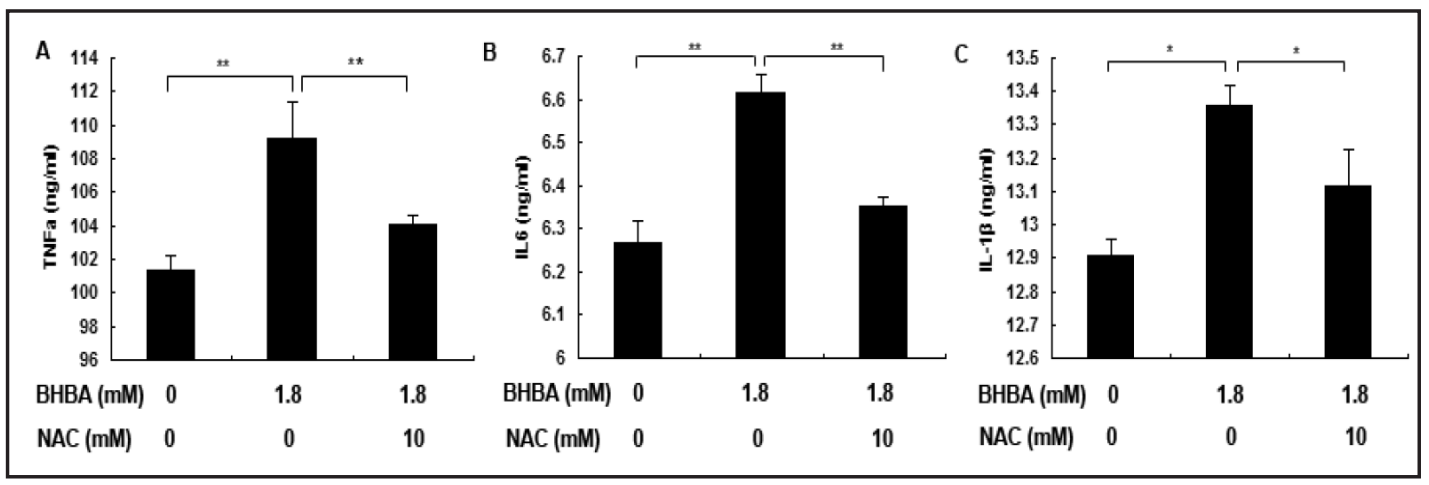

Fig. 6. NAC suppressed the expression of pro-inflammatory factor in calf hepatocytes. Hepatocytes were treated with 0, $1.8 \mathrm{mM}$ BHBA, $10 \mathrm{mM}$ NAC + $1.8 \mathrm{mM}$ BHBA (NAC + BHBA). (A) ELISA of TNF- $\alpha$. (B) ELISA of IL-6. (C) ELISA of IL-1 $\beta$. The data are shown as the mean \pm SEM. * , statistical significance $(\mathrm{P}<0.05) .{ }^{* *}$, statistical significance $(\mathrm{P}<0.01)$. The symbol ${ }^{*}$ and ${ }^{* *}$ indicate that the two groups which marked with horiziontal line are statistical differences.

that high concentrations of BHBA could increase the expression and synthesis of the proinflammatory factors TNF- $\alpha$, IL- 6 and IL- $1 \beta$ in primary calf hepatocytes. These results indicate that the inflammatory response is stimulated by high concentrations of BHBA in hepatocytes, which is in agreement with some studies that reported such a positive influence of elevated concentrations of BHBA on inflammation in endometritis and mastitis in dairy cattle $[10,11,24]$, supporting our results that BHBA can raise pro-inflammatory factors in hepatocytes.

The NF- $\mathrm{BB}$ transcription factor family is composed of the most critical regulators of the immediate transcriptional responses in inflammatory situations [25]. I $\mathrm{K} \alpha \alpha$ phosphorylation is dependent on IKK $\beta$ activity, which is important for the release of active NF- $\kappa B$ [16]. To further demonstrate that the release of the pro-inflammatory cytokines TNF- $\alpha$, IL- 6 and IL-1 $\beta$ after BHBA treatment may occur through the NF- $\kappa B$ pathway, the activity of IKK $\beta$, phosphorylated I $\kappa B \alpha$ and NF- $\kappa B$ p65 were detected in BHBA-treated cattle hepatocytes. In this study, we demonstrated that BHBA increased IKK $\beta$ activity, induced I $\kappa B \alpha$ phosphorylation and promoted the transfer of NF- $\kappa B$ p65 to the nucleus. However, in the PDTC + BHBA group, $\mathrm{p}-\mathrm{I} \kappa \mathrm{B} \alpha$ and NF- $\kappa \mathrm{B}$ p 65 were inhibited. Taken together, these results demonstrate that BHBA can activate the NF- $\kappa$ B pathway in cattle hepatocytes. Here, we also demonstrated that the mRNA expression and release of TNF- $\alpha$, IL- 6 and IL- $1 \beta$ were markedly inhibited in the PDTC + BHBA group, which further demonstrated that BHBA could activate the NF- $\kappa$ B pathway to regulate the release of the pro-inflammatory factors TNF- $\alpha$, IL- 6 and IL- $1 \beta$ in cattle hepatocytes. IL- 6 was markedly increased in cows with ketosis and played a central role in the impairment of normal liver functions of transition cows [26]. IL-1 $\beta$ was markedly increased in xanthine oxidase-induced liver injury in type I diabetic rats [17]. TNF- $\alpha$ could promote liver triglyceride accumulation and increase the risk of fatty liver in late-lactating Holstein cows [27]. These findings indicate that greater concentrations of BHBA activate the NF- $\kappa B$ pathway to increase the expression of TNF- $\alpha$, IL- 6 and IL-1 $\beta$, thereby inducing hepatocyte injury. Thus, we speculate that high concentrations of BHBA can induce liver injury by activating the NF- $\mathrm{BB}$ signaling pathway-mediated expression of pro-inflammatory factors in dairy cattle with ketosis.

$\mathrm{NF}-\mathrm{\kappa B}$ activation is highly dependent on oxidative stress, which is associated with the immune response $[17,28]$. An imbalance in oxidants/antioxidants, an excess of oxidants and/or a depletion of antioxidants, can lead to oxidative stress [21, 29]. Oxidative stress is not a classical disease and does not exhibit a specific clinical symptoms, it is one of the basics of some metabolic diseases such as ketosis. Dairy cows undergoing ketosis experience oxidative stress which can be measured in biological fluids and tissues [5, 30, 31]. MDA is one of the final products of polyunsaturated fatty acid peroxidation, which is caused by 
increasing level of reactive oxygen species (ROS) and is commonly known as a marker of oxidative damage [32]. NO acts intracellularly, and excess NO can cause oxidative stress [33]. iNOS mainly catalyzes NO formation, which can induce oxidative stress [34]. Superoxide dismutases (SOD: Mn SOD and Cu/Zn SOD) and catalase (CAT) are two important antioxidant enzymes involved in the removal of ROS [35, 36]. GSH-Px is involved in catalyzing the GSHdependent reduction of hydrogen peroxide [36]. In this study, we have demonstrated that BHBA increased the levels of MDA, iNOS and NO. Moreover, the levels of SOD, CAT and GSHPx were significantly decreased in the BHBA-treated hepatocytes.

These results demonstrate that BHBA can increase the oxidants status and decrease the antioxidants status. Indeed, as it was shown, greater concentration of BHBA could lead to the higher levels of indices of oxidative status: reactive oxygen metabolites (ROM) and thiobarbituric acid reactive substances (TBARS), and lower levels of antioxidants in the plasma of dairy cows thereby leading to oxidative stress [5]. Pedernera et al. [21] measured indicators of energy balance (non-esterified fatty acids, $\beta$-hydroxybutyrate, glucose and insulin-like growth factor-1) and indicators of oxidative stress (reactive oxygen metabolites and biological antioxidants) in the first 5 weeks of lactation. They found that oxidative stress was related to NEB in dairy cow. Additional reports found that ketone bodies served as oxidative fuel and lipogenic precursors in cells, oxidative fuel could improve mitochondrial respiration and ATP production, and then increase mitochondria piece production [8, 37]. Excessive fat mobilization might impair liver function due to intracellular lipid accumulation [38], and cows with hepatomegaly have reduced capacity to produce antioxidants [39]. These reports supported our findings that BHBA could induce oxidative stress in the hepatocytes of dairy cattle. Additionally, Czaja [18] reported that the common mechanism of liver injury was oxidative stress. This study has shown that BHBA activated NF- $\mathrm{KB}$-induced hepatocyte injury by regulating the expression of TNF- $\alpha$, IL- 6 and IL- $1 \beta$ in hepatocytes. Additionally, we found that the quantities of pro-inflammatory factors TNF- $\alpha$, IL- 6 and IL- $1 \beta$ were significantly reduced by treating for antioxidant NAC in cattle hepatocytes. It demonstrated that the pro-inflammatory responses were induced by oxidative stress. Therefore, we infer that oxidative stress most likely plays a role in modulating the inflammatory response through the activation of the NF- $\mathrm{BB}$ pathway. Indeed, the important oxidative marker MDA had been reported to correlate significantly with $\mathrm{I} \kappa \mathrm{B} \alpha$ phosphorylation and $\mathrm{p} 65 \mathrm{NF}-\kappa \mathrm{B}$ migration to the nucleus [40]. However, the particular mechanism of how oxidative stress activates the NF- $\kappa B$ pathway in dairy cattle is worthy of further study.

The finding that BHBA-induced oxidative stress activates the NF- $\kappa B$ pathway in cattle hepatocytes is novel. However, how BHBA induces the oxidative stress in cattle hepatocytes is unknown. Additionally, whether other signal pathways are involved in inducing inflammation or whether NF- $\kappa \mathrm{B}$ has another effect on cattle hepatocytes are also unknown. Therefore, future studies should aim to confirm the specific mechanism of BHBA-induced oxidative stress and confirm the relationship between NF- $\mathrm{KB}$ and other signaling pathways in cattle hepatocytes.

\section{Conclusions}

Taken together, these results indicate that BHBA can induce the activation of the NF$\kappa B$ signaling pathway in cattle hepatocytes by the upregulation of oxidative markers (iNOS, MDA and NO) and downregulation of antioxidative markers (SOD, CAT and GSH-Px). NF- $\kappa B$ induces hepatocyte injury by translocating to the nucleus and increasing the DNA binding activity to increase the transcription of the pro-inflammatory factors TNF- $\alpha$, IL- 6 and IL-1 $\beta$. The current study identifies a mechanism by which BHBA can regulate inflammatory injury in the hepatocytes of dairy cattle.

\section{Conflict of Interest}

None to declare. 


\section{Acknowledgements}

This work was supported by the National Key Technology R\&D Program (grant no. 2012BAD12B03), the National High Technology R\&D Program (863 Program) (No. 2013AA102806), the Program for Changjiang Scholars and Innovative Research Team in University (PCSIRT, No. IRT1248), the National Natural Science Foundation of China (Beijing, China; grant nos. 30871897, 30972224, 31072178, 31172372, 31272621, 31360630, 31372478 and 31372494) and the Program for New Century Excellent Talents in University (NCET-11-0199).

\section{References}

1 Lai HS, Lin WH, Chen PR, Wu HC, Lee PH, Chen WJ: Effects of a high-fiber diet on hepatocyte apoptosis and liver regeneration after partial hepatectomy in rats with fatty liver. JPEN J Parenter Enteral Nutr 2005;29:401-407.

- McArt JA, Nydam DV, Oetzel GR, Overton TR, Ospina PA: Elevated non-esterified fatty acids and $\beta$-hydroxybutyrate and their association with transition dairy cow performance. Vet J 2013;16. pii:S1090-0233(13)00386-9.

3 Xu C, Wang Z, Liu GW, Li XB, Xie GH, Xia C, Zhang HY: Metabolic characteristic of the liver of dairy cows during ketosis based on comparative proteomics. Asian Aust J Anim 2008;2:1003-1010.

4 Li X, Li X, Chen H, Lei L, Liu J, Guan Y, Liu Z, Zhang L, Yang W, Zhao C, Fu S, Li P, Liu G, Wang Z: Non-Esterified Fatty Acids Activate the AMP-Activated Protein Kinase Signaling Pathway to Regulate Lipid Metabolism in Bovine Hepatocytes. Cell Biochem Biophys DOI: 10.1007/2013-013-9629-1.

-5 Bernabucci U, Ronchi B, Lacetera N, Nardone A: Influence of body condition score on relationships between metabolic status and oxidative stress in periparturient dairy cows. J Dairy Sci 2005;88:2017-2026.

6 Laeger T, Metges CC, Kuhla B: Role of beta-hydroxybutyric acid in the central regulation of energy balance. Appetite 2010;54:450-455.

7 Cheng S, Chen GQ, Leski M, Zou B, Wang Y, Wu Q: The effect of D,L-beta-hydroxybutyric acid on cell death and proliferation in L929 cells. Biomaterials 2006;27:3758-3765.

8 Laeger T, Pöhland R, Metges CC, Kuhla B: The ketone body $\beta$-hydroxybutyric acid influences agoutirelated peptide expression via AMP-activated protein kinase in hypothalamic GT1-7 cells. J Endocrinol 2012;213:193-203.

-9 Nakamura S, Shibuya M, Saito Y, Nakashima H, Saito F, Higuchi A, Tsubota K: Protective effect of D-betahydroxybutyrate on corneal epithelia in dry eye conditions through suppression of apoptosis. Invest Ophthalmol Vis Sci 2003;44:4682-4688.

10 LeBlanc SJ, Osawa T, Dubuc J: Reproductive tract defense and disease in postpartum dairy cows. Theriogenology 2011;76:1610-1618.

11 Hammon DS, Evjen IM, Dhiman TR, Goff JP, Walters JL: Neutrophil function and energy status in Holstein cows with uterine health disorders. Vet Immunol Immunopathol 2006;113:21-29.

-12 Fan C, Li Q, Zhang Y, Liu X, Luo M, Abbott D, Zhou W, Engelhardt JF: IkappaBalpha and IkappaBbeta possess injury context-specific functions that uniquely influence hepatic NF-kappaB induction and inflammation. J Clin Invest 2004;113:746-755.

13 Luedde T, Assmus U, Wüstefeld T, Meyer zu Vilsendorf A, Roskams T, Schmidt-Supprian M, Rajewsky K, Brenner DA, Manns MP, Pasparakis M, Trautwein C: Deletion of IKK2 in hepatocytes does not sensitize these cells to TNF-induced apoptosis but protects from ischemia/reperfusion injury. J Clin Invest 2005;115:849-859.

14 Hayden MS, Ghosh S: Shared principles in NF-kappaB signaling. Cell 2008;132:344-362.

$\checkmark 15$ Hatada EN, Nieters A, Wulczyn FG, Naumann M, Meyer R, Nucifora G, McKeithan TW, Scheidereit C: The ankyrin repeat domains of the NF-kappa B precursor p105 and the protooncogene bcl-3 act as specific inhibitors of NF-kappa B DNA binding. Proc Natl Acad Sci U S A 1992;89:2489-2493.

16 Siomek A: NF-кB signaling pathway and free radical impact. Acta Biochim Pol 2012;59:323-331. 
17 Romagnoli M, Gomez-Cabrera MC, Perrelli MG, Biasi F, Pallardó FV, Sastre J, Poli G, Viña J: Xanthine oxidaseinduced oxidative stress causes activation of NF-kappaB and inflammation in the liver of type I diabetic rats. Free Radic Biol Med 2010;49:171-177.

18 Czaja MJ: Cell signaling in oxidative stress-induced liver injury. Semin Liver Dis 2007;27:378-389.

19 Ji LL, Gomez-Cabrera MC, Vina J: Exercise and hormesis: activation of cellular antioxidant signaling pathway. Ann N Y Acad Sci 2006;1067:425-435.

20 Abuelo A, Hernández J, Benedito JL, Castillo C: Oxidative stress index (OSi) as a new tool to assess redox status in dairy cattle during the transition period. Animal 2013;7:1374-1378.

-21 Pedernera M, Celi P, Garcia SC, Salvin HE, Barchia I, Fulkerson WJ: Effect of diet, energy balance and milk production on oxidative stress in early-lactating dairy cows grazing pasture. Vet J 2010;186:352-357.

22 Li X, Chen H, Guan Y, Li X, Lei L, Liu J, Yin L, Liu G, Wang Z: Acetic acid activates the AMP-activated protein kinase signaling pathway to regulate lipid metabolism in bovine hepatocytes. PLoS One 2013;8:e67880.

23 Iwersen M, Klein-Jöbstl D, Pichler M, Roland L, Fidlschuster B, Schwendenwein I, Drillich M: Comparison of 2 electronic cowside tests to detect subclinical ketosis in dairy cows and the influence of the temperature and type of blood sample on the test results. J Dairy Sci 2013;96:7719-7730.

24 Galvão KN, Flaminio MJ, Brittin SB, Sper R, Fraga M, Caixeta L, Ricci A, Guard CL, Butler WR, Gilbert RO: Association between uterine disease and indicators of neutrophil and systemic energy status in lactating Holstein cows. J Dairy Sci 2010;93:2926-2937.

25 Denk A, Wirth T, Baumann B: NF-kappaB transcription factors: critical regulators of hematopoiesis and neuronal survival. Cytokine Growth Factor Rev 2000;11:303-320.

26 Loor JJ, Everts RE, Bionaz M, Dann HM, Morin DE, Oliveira R, Rodriguez-Zas SL, Drackley JK, Lewin HA: Nutrition-induced ketosis alters metabolic and signaling gene networks in liver of periparturient dairy cows. Physiol Genomics 2007;32:105-116.

27 Bradford BJ, Mamedova LK, Minton JE, Drouillard JS, Johnson BJ: Daily injection of tumor necrosis factor\{alpha\} increases hepatic triglycerides and alters transcript abundance of metabolic genes in lactating dairy cattle. J Nutr 2009;139:1451-1456.

28 Hybertson BM, Gao B, Bose SK, McCord JM: Oxidative stress in health and disease: the therapeutic potential of Nrf2 activation. Mol Aspects Med 2011;32:234-246.

29 MacNee W: Oxidants/antioxidants and COPD. Chest 2000;117:303-317.

30 Sordillo LM, Aitken SL: Impact of oxidative stress on the health and immune function of dairy cattle. Vet Immunol Immunopathol 2009;128:104-109.

-31 El-Deeb WM, Younis EE: Clinical and biochemical studies on Theileria annulata in Egyptian buffaloes (Bubalus bubalis) with particular orientation to oxidative stress and ketosis relationship. Vet Parasitol 2009;164:301-305.

- 32 Del Rio D, Stewart AJ, Pellegrini N: A review of recent studies on malondialdehyde as toxic molecule and biological marker of oxidative stress. Nutr Metab Cardiovasc Dis 2005;15:316-328.

-33 Brown GC: Regulation of mitochondrial respiration by nitric oxide inhibition of cytochrome c oxidase. Biochim Biophys Acta 2001;1504:46-57.

-34 Gao YT, Panda SP, Roman LJ, Martásek P, Ishimura Y, Masters BS: Oxygen metabolism by neuronal nitricoxide synthase. J Biol Chem 2007;282:7921-7929.

-35 Michiels C, Raes M, Toussaint O, Remacle J: Importance of Se-glutathione peroxidase, catalase, and Cu/ZnSOD for cell survival against oxidative stress. Free Radic Biol Med 1994;17:235-248.

-36 Gutteridge JM, Halliwell B: Free radicals and antioxidants in the year 2000. A historical look to the future. Ann N Y Acad Sci 2000;899:136-147.

-37 Hawkins RA, Biebuyck JF: Ketone bodies are selectively used by individual brain regions. Science 1979;205:325-327.

-38 Grummer RR: Etiology of lipid-related metabolic disorders in periparturient dairy cows. J Dairy Sci 1993;76:3882-3896.

39 Turk R, Juretic D, Geres D, Turk N, Simeon-Rudolf V, Rekic B, Svetina A: Oxidative stress in dairy cows serum paraoxonase activity related to hepatomegaly. Croatica Chemica Acta 2005;78:375-378.

40 Nandakumar DN, Koner BC, Vinayagamoorthi R, Nanda N, Negi VS, Goswami K, Bobby Z, Hamide A: Activation of NF-kappaB in lymphocytes and increase in serum immunoglobulin in hyperthyroidism: possible role of oxidative stress. Immunobiology 2008;213:409-415. 